\title{
Efficacy of combination of oral mifepristone and vaginal misoprostol in termination of pregnancy up to 63 days of gestation
}

\author{
Shivani Gupta* \\ Department of Obstetrics and Gynecology, Dr. S. N. Medical College, Jodhpur, Rajasthan, India \\ Received: 18 September 2019 \\ Accepted: 25 October 2019 \\ *Correspondence: \\ Dr. Shivani Gupta, \\ E-mail: dr.shivani2686@gmail.com \\ Copyright: (C) the author(s), publisher and licensee Medip Academy. This is an open-access article distributed under \\ the terms of the Creative Commons Attribution Non-Commercial License, which permits unrestricted non-commercial \\ use, distribution, and reproduction in any medium, provided the original work is properly cited.
}

\begin{abstract}
Background: Unsafe and illegal abortions are one of the major problems in women health in India. Despite legal approval for medical termination of pregnancy in 1971, unsafe abortion still remains the third leading cause of maternal deaths in the country, contributes eight percent of such deaths annually. The objective of this study was to study efficacy of Mifepristone $200 \mathrm{mg}$ orally followed 36-48 hours later by Misoprostol 800 microgms per vaginally in women undergoing medical termination of early pregnancy (up to 63 days of gestational age).

Methods: The present study included 60 pregnant women requesting termination of pregnancy in the first trimester. Women who fulfilled the inclusion criteria were included in the study. Women without medical or surgical contraindications to Mifepristone and Misoprostol were included. Patients with previous caesarean sections were also included.

Results: In our study 60 women were included, majority were in age group 20-29 years of age and majority of cases were primipara or multipara. The success rate in terms of complete abortion was $97 \%, 2 \%$ needed surgical evacuation and $1 \%$ lost to follow up. Side effects were nausea, vomiting, diarrhoea, abdominal cramps, pyrexia etc. The method proved to be safe, effective, cheap, non-invasive and has minimal or no complications.

Conclusions: Medical termination of pregnancy with oral mifepristone and vaginal misoprostol is an effective method for first trimester abortion. The prerequisite for the method is patient counselling, patient participation and willingness for regular follow up and to report any complication. Hence this method comes out to be a safe alternative to surgical method which is invasive and costly.
\end{abstract}

Keywords: Caesarean sections, Mifepristone, Misoprostol

\section{INTRODUCTION}

Millions of unwanted and unplanned pregnancies occur all over the world owing to lack of awareness of family planning measures. These unintended pregnancies increase the population burden if continued till term or landed up to illegal and unsafe abortions. Despite wider availability of contraceptive methods, the incidence of induced abortions is increasing. According to a recent survey, $13 \%$ of 1.5 crore women who opt for abortion to terminate their pregnancy lose their life every year. ${ }^{1}$ These are mainly due to illegal abortions. During 20102014, an estimated 56 million induced abortion occurred every year worldwide. Out of them 25 million (45\%) are unsafe. $^{2}$ Almost there is one unsafe abortion for every ten pregnancies or one abortion every seven life births. ${ }^{3}$ In India, 15.6 million abortions occurred in 2015, out of them 11.5 million $(73 \%)$ were done outside the health facilities. ${ }^{4}$ So there is a need of safe, inexpensive and easy abortion method. 
Medical abortion provides a better alternative to surgical evacuation especially in a low resource country like India. Various regimes are being used for termination of pregnancy. Our study was undertaken to determine the efficacy and side effects of oral mifepristone $200 \mathrm{mg}$ and misoprostol $800 \mathrm{mcg}$ vaginally after 48 hours.

\section{METHODS}

60 cases were studied prospectively with pregnancy up to 63 days of gestation opting for voluntary medical termination of pregnancy during six months duration (January 2019 to June 2019). Ethical clearance and pre consent procedure (under MTP act 1972) were done. Vital baseline parameters like pulse, BP and temperature were recorded. Systemic examination with per abdominal, per speculum and per vaginal examination were done. All the concerned patients underwent basic investigations including hemogram, blood grouping and typing, urine routine examination, blood sugar level (R), Austria antigen, VDRL and HIV. Ultrasonography was done before to determine exact gestation age and to confirm intrauterine location of pregnancy. Scanning was done later to assure complete abortion. Further patients were informed regarding dose of the drug, the side effects, the number of visits required and the need for surgical evacuation in case of failure.

\section{Inclusion criteria}

- $\quad$ Patients with singleton live gestation till 63 days (9 weeks) seeking abortion services for valid indication under the MTP Act

- Patients willing to give written consent and regular follow up visits

- Patients willing for surgical intervention in case of failure of medical method.

\section{Exclusion criteria}

- Patients with multiple pregnancies

- Patients with intrauterine device in situ

- Patients with haemoglobin $<8.5 \mathrm{gm} / \mathrm{dl}$

- Patients with history of major medical illnesses or allergic issues

- Patients not willing to give consent.

All the included patients were given $200 \mathrm{mg}$ of mifepristone. After 48 hours, patients were called back and $800 \mathrm{mcg}$ of misoprostol (four tablets of $200 \mathrm{mcgs}$ each) was administered per vaginum and were observed for 6 hours. Patients were again called after 15 days. Clinical evaluation, history regarding side effects, per vaginal examination and transvaginal ultrasonography was done to ensure complete abortion.

Outcome were assessed as complete abortion (complete expulsion of products of conception with no need for surgical evacuation) and incomplete abortion (persistent gestational sac, excessive or prolonged uterine bleeding requiring surgical intervention). Women who did not respond to medical treatment within 24 hours of misoprostol administration, were offered surgical methods for termination of pregnancy.

\section{Statistical analysis}

Statistical analysis was done for differences in onset of bleeding after misoprostol administration and side effects among primigravida and multigravida.

\section{RESULTS}

A total of 60 patients were studied. Maternal characteristics are shown in Table 1. Majority of patients were seen in age between 26 and 30 years. Only 10\% patients were primigravida as only married women were included in the present study. Majority of patients did not have prior abortion. There were 7 cases of previous one LSCS and 3 cases of previous two LSCS. Maximum numbers of cases were in gestational age between 36-50 days. The average induction abortion time in the study was 5.26 hours. About $70 \%$ patients aborted within 8 hours and all the patients aborted within 24 hours (Table 2).

Table 1: Maternal characteristics.

\begin{tabular}{|lll|}
\hline $\begin{array}{l}\text { Maternal } \\
\text { characteristics }\end{array}$ & $\begin{array}{l}\text { Number of } \\
\text { patients }\end{array}$ & Percentage \\
\hline Age distribution & & \\
\hline $18-20$ & 2 & 3 \\
\hline $21-25$ & 17 & 28 \\
\hline $26-30$ & 20 & 33 \\
\hline $31-35$ & 16 & 26 \\
\hline$>36$ & 5 & 10 \\
\hline Parity & & \\
\hline Primi & 7 & 11 \\
\hline Para & 20 & 33 \\
\hline Para & 26 & 45 \\
\hline Para & 7 & 11 \\
\hline Previous abortions & & \\
\hline 1 & 8 & 13 \\
\hline 2 & 2 & 3 \\
\hline 3 & 1 & 1.6 \\
\hline Previous LSCS & & 11 \\
\hline Previous 1 LSCS & 7 & 5 \\
\hline Previous 2 LSCS & 3 & 28 \\
\hline Gestation age (by USG) & 17 & 42 \\
\hline 20-35days & 25 & 24 \\
\hline $36-50$ days & 14 & \\
\hline $51-60$ days & 4 & \\
\hline $66-80$ days & & \\
\hline
\end{tabular}

There was a statistically significant difference in the onset of bleeding among primigravida (6.12 \pm 0.42 hours) and multigravida (5.05 \pm 0.55 hours $) \quad(p<0.0001)$. However, there was no statistically significant difference 
found in onset of bleeding between previous LSCS and previous normal delivered patients.

Table 2: Induction abortion interval.

\begin{tabular}{|lll|}
\hline $\begin{array}{l}\text { Induction abortion } \\
\text { interval }\end{array}$ & No. of cases & Percentage \\
\hline Within 5 hours & 30 & 50 \\
\hline Within 8 hours & 45 & 75 \\
\hline Within 24 hours & 60 & 100 \\
\hline
\end{tabular}

In present study, 56 (94\%) patients had complete abortion. 4 patients $(6 \%)$ had incomplete abortion. In 2 of the above repeat 200 misoprostol vaginally resulted in complete abortion within 7 days, remaining 2 needed surgical evacuation because of heavy bleeding (Table 3 ).

Table 3: Completeness of procedure.

\begin{tabular}{|lll|}
\hline Abortion & No. of cases & Percentage \\
\hline Complete abortion & 56 & 94 \\
\hline Incomplete abortion & 4 & 6 \\
\hline
\end{tabular}

Majority of the patients, $42(71 \%)$ experienced abdominal cramps, nausea in $12(20 \%)$, vomiting in $10(16 \%)$, diarrhoea in $5(8 \%)$ and excessive bleeding in $2(3 \%)$, (Table 4). Majority of patients presented with more than one side effects and within 3 days of misoprostol administration. There was statistically significant association between age $\leq 30$ years and there were side effects like abdominal cramps $(\mathrm{p}<0.01)$, nausea $(\mathrm{p}<$ $0.05)$ and diarrhoea $(\mathrm{p}<0.05)$.

Table 4: Side effects related to drugs used.

\begin{tabular}{|lll|}
\hline Side effects & No. of cases & Percentage \\
\hline Abdominal cramps & 42 & 71 \\
\hline Nausea & 12 & 20 \\
\hline Vomiting & 10 & 16 \\
\hline Diarrhoea & 5 & 8 \\
\hline Excessive bleeding & 2 & 3 \\
\hline
\end{tabular}

\section{DISCUSSION}

Unsafe abortion is a major cause of mortality among women in India accounting for approximately $15 \%$ of maternal deaths. Currently in India, mifepristone has been approved for use in medical termination of intrauterine pregnancy up to 63 days. Various regimes of combined mifepristone and misoprostol have been studied in different studies with efficacy up to 63 days of gestation. Comparative trials have shown that a reduction in the oral dose of mifepristone from 600 to $200 \mathrm{mg}$ does not affect the efficacy in termination of early pregnancy.

In the present study, $200 \mathrm{mg}$ of mifepristone and $800 \mathrm{mcg}$ of misoprostol were used in women with gestation age up to 80 days. Complete abortion occurred in $94 \%$ of cases. Our results are consistent with similar studies in past.
Ashok et al, studied the result of $200 \mathrm{mg}$ oral mifepristone with $500 \mathrm{mcg}$ of vaginal misoprostol till gestation age $<49$ days and $<63$ days in 928 patients. $^{5}$ The success rate was $98.5 \%$ (< 49 days) and $96.5 \%(<63$ days).

Kumar $\mathrm{S}$ et al, found complete abortion by medical abortion in $95.6 \%$ of patients. ${ }^{6}$ Similarly, Grossman D et al, found complete abortion rate by medical abortion in $93.8 \%$ of cases. $^{7}$

Silvestre L et al, and Nicholas CW Hill, studied different prostaglandin composition with mifepristone and found similar efficacy of different regimes. ${ }^{8,9}$

Elaine et al, used $200 \mathrm{mcg}$ of mifepristone and $500 \mathrm{mcg}$ of misoprostol, found a success rate of $94.5 \%$ in 253 patients of gestational age, 63-85 days. ${ }^{10}$

Although no relevant literature references available for association between age of the patient and the incidence of side effects, in the current study, there was a statistically significant association between age $\leq 30$ years and side effects like abdominal cramps $(\mathrm{p}<0.001)$, nausea $(p<0.05)$ and diarrhoea $(p<0.05)$. Further time of onset of bleeding after misoprostol administration was statistically significant in both primigravida and multigravida. [primigravida $(6.12 \pm 0.42$ hour $)$ and multigravida $(5.05 \pm 0.55$ hour $)$ ( $\mathrm{p}<0.0001)$.] However, there was no statistically significant difference found in onset of bleeding between previous LSCS and previous normal delivered patients.

\section{CONCLUSION}

Medical abortion with $200 \mathrm{mg}$ and $800 \mathrm{mcg}$ vaginal misoprostol has proved to be a safe, reliable and noninvasive method. Surgical measures have inherent association of anaesthetic complications, genital tract infection and increased cost. In developing countries like India with limited operation theatre setup and cost restraints, medical abortion may prove a boon to combat the ongoing problem of unsafe abortion. This may boost up the reproductive health of women.

However, medical abortion requires active participation of health professionals and patients in terms of proper counselling, consent proceedings and regular follow-up.

Funding: No funding sources

Conflict of interest: None declared

Ethical approval: The study was approved by the Institutional Ethics Committee

\section{REFERENCES}

1. Bilandani N. Abortion kills 20 lakh women every year, 2017. Available at: http://thecsrjournal.in. Accessed on $10^{\text {th }}$ August 2019. 
2. Induced abortion worldwide- Guttmacher Institute Available at: http://www.guttmacher.org. Accessed on $20^{\text {th }}$ August 2019.

3. Ahman E, Shah I. Unsafe abortion: global and regional estimates of the incidence of unsafe abortion and associated mortality in 2003. 2007.

4. Singh S, Shekhar C, Acharya R, Moore AM, Stillman M, Pradhan MR, et al. The incidence of abortion and unintended pregnancy in India, 2015. The Lancet Global Health. 2018;6(1):e111-20.

5. Ashok PW, Penny GC, Flett GM, Templeton A. An effective regimen for early medical abortion: a report of 2000 consecutive cases, Hum Reprod. 1998;13:2962-5.

6. Kumar S, Patreka M, Deshpande H. A prospective trial using mifepristone and vaginal misoprostol in termination of pregnancies up to 63 days of gestation. Obstet Gynecol India. 2014;63(6):370-2.

7. Grossman D. Medical methods for first trimester abortion: RHL commentary. The WHO Reproductive Health Library. Geneva: World Health Organization. 2004.

8. Peyron R, Aubeny E, Targosz V, Silvestre L, Renault M, Elkik F, et al. Early termination of pregnancy with mifepristone (RU 486) and the orally active prostaglandin misoprostol. New Eng J Med. 1993;328(21):1509-13.

9. Ulmann A, Silvestre L, Chemama L, Rezvani Y, Renault M, Aguillaume CJ, et al. Medical termination of early pregnancy with mifepristone (RU 486) followed by a prostaglandin analogue: Study in 16, 369 women. Acta Obstet Gynaecol Scand., 1992;71:278-83.

10. Hill NC, Ferguson J, MacKenzie IZ. The efficacy of oral Mifepristone (RU 38,486) with a prostaglandin E1 analog vaginal pessary for the termination of early pregnancy: complications and patient acceptability. Am J Obstet Gynecol. 1990;162:414-7.

Cite this article as: Gupta S. Efficacy of combination of oral mifepristone and vaginal misoprostol in termination of pregnancy up to 63 days of gestation. Int J Reprod Contracept Obstet Gynecol 2019;8:4951-4. 